\title{
$248 \quad$ IS DYSTROPHIN ABSENCE IMPLICATED IN THE TRANSITION FROM PHYSIOLOGICAL TO PATHOLOGICAL CARDIAC HYPERTROPHY?
}

C Prado, V Blefari, D Oliveira, C A Silva, R Fazan, H C Salgado, M A Rossi University of Sao Paulo

doi:10.1136/heartjnl-2013-304019.248

Hypertension causes cardiac hypertrophy, cardiac dysfunction, and heart failure (HF). The mechanisms implicated in the transition from physiological to pathological hypertrophy are still unknown. Growing evidence points out to the role of inappropriate mechanical coupling in the pathogenesis of HF and the cytoskeletal proteins as the most obvious candidates for intracellular remodeling. We investigated dystrophin and its potential role in the pathogenesis of HF in rats submitted to chronic abdominal aorta stenosis. Wistar rats were submitted to abdominal aorta stenosis and killed at 30,60 and 90 days post surgery. The hearts were collected and Western blot (WB) and immunofluorescence (IF) were performed for dystrophin. Blood pressure was evaluated and cardiac function evaluate by echocardiography. Data were considered significant when $\mathrm{p}<0.05$. At $90 \mathrm{~d} 70 \%$ presented hypertrophied hearts $(\mathrm{HH})$ and $30 \%$ hypertrophied and dilated hearts $(\mathrm{DH})$, as evaluated by echocardiography. Blood pressure increased 53, 42\% 30d, 50, 8\% $60 \mathrm{~d}$ and $64,36 \%$ at $60 \mathrm{~d}$ post surgery. Dystrophin expression reduced $15 \% 30 \mathrm{~d}, 22 \% 60 \mathrm{~d}$ and $26 \%$ at $90 \mathrm{~d}$ post surgery in $\mathrm{HH}$ and $31 \%$ in $\mathrm{DH}$. The ejection fraction was the same as control at $30 \mathrm{~d}$ and $60 \mathrm{~d}$ post surgery, however it was reduced $35 \%$ at $90 \mathrm{~d}$ in $\mathrm{HH}$ and $48 \%$ in DH. Dystrophin absence may be partly responsible for the development of heart failure in rats submitted to chronic abdominal aorta stenosis. Thus, it is essential to define the mechanistic aspects of the pathophysiological processes involved in deterioration of cardiac function and design develop strategies to inhibit and/or reverse evolution of heart hypertrophy from compensated to decompensated phase. Grants from FAPESP 09/177878; 09/54010-1; 10/19216-5. 